This document is the author's pre-print version of this article, i.e. the final draft version after review. The final document is available in International Wood Products Journal and can be viewed online by using the dx.doi.org/10.1179/2042645313Y.0000000046. We also refer to this URL for citing details.

Van den Bulcke, J., Biziks, V., Andersons, B., Mahnert, K.C., Militz, H., Van Loo, D., Dierick, M., Masschaele, B., Boone, M.N., Brabant, L. and De Witte, Y., 2013. Potential of X-ray computed tomography for 3D anatomical analysis and microdensitometrical assessment in wood research with focus on wood modification. International Wood Products Journal, 4(3), pp.183-190. 


\section{The potential of X-ray computed tomography for 3D anatomical analysis and microdensitometrical assessment in wood research with focus on wood modification}

Jan $\underline{\text { Van den Bulcke }}^{1,2}$, Vladimirs Biziks ${ }^{3}$, Bruno $\underline{\text { Andersons }}^{3}$, KarlChristian Mahnert ${ }^{4,5}$, Holger Militz, Denis Van Loo ${ }^{2,6}$, Manuel Dierick $^{2,6}$, Bert Masschaele ${ }^{2,6}$, Matthieu Boone ${ }^{2,6}$, Loes Brabant ${ }^{2,6}$, Yoni De Witte $^{2,6}$, Jelle Vlassenbroeck ${ }^{7}$, Luc Van Hoorebeke ${ }^{2,6}$, Joris ${\text { Van } \text { Acker }^{1,2}}^{2}$

\footnotetext{
${ }^{1}$ Woodlab-UGent, Ghent University, Department of Forest and Water Management, Faculty of Bioscience Engineering, Coupure Links 653, 9000 Ghent, Belgium [email: Jan.VandenBulcke@UGent.be; Joris.VanAcker@UGent.be]

2 UGCT, University Ghent Centre for X-ray Tomography, Proeftuinstraat 86, 9000 Gent, Belgium

3 Latvian State Institute of Wood Chemistry, Dzerbenes 27, LV-1006, Riga, Latvia [orkaans79@inbox.Iv; bruno.andersons@edi.lv]

4 University of Göttingen, Burckhardt Institute, Department of Wood Biology and Wood Technology, Büsgenweg 4, D-37077 Göttingen [karl.mahnert@treteknisk.no; hmilitz@gwdg.de]

${ }^{5}$ since 04/2012: Treteknisk, Forskningsveien 3B, NO-0373 Oslo [karl.mahnert@treteknisk.no]

${ }^{6}$ Ghent University, Department of Physics and Astronomy, Institute for Nuclear Sciences, Proeftuinstraat 86, 9000 Ghent, Belgium [Denis.VanLoo@UGent.be; Manuel.Dierick@UGent.be; Bert.Masschaele@UGent.be; Matthieu.Boone@UGent.be; Loes.Brabant@UGent.be; Luc.VanHoorebeke@UGent.be]

7 inCT, Technologiepark 3, 9052 Zwijnaarde, Belgium [info@inct.be]
} 


\begin{abstract}
Studying structure and chemistry of wood and wood-based materials is the backbone of all wood research and many techniques are at hand to do so. A very valuable modality is X-ray CT, able to non-destructively probe the three-dimensional structure and composition. In this paper we elaborate on the use of Nanowood, a flexible multiresolution X-ray computed tomography (X-ray CT) setup developed at UGCT, the Ghent University Centre for X-ray Tomography. The technique has been used successfully in many different fields of wood science. It is illustrated how 3D structural and microdensitometrical data can be obtained using different scan set-ups and protocols. Its potential for the analysis of modified wood is exemplified, a.o. for the assessment of wood treated with hydrophobing agents, localisation of modification agents, pathway analysis related to functional tissues, dimensional changes due to thermal treatment, etc. Furthermore, monitoring of transient processes is a promising field of activity too.
\end{abstract}

Keywords: microdensitometry; multi-resolution X-ray computed tomography; modified wood; quantitative wood anatomy; structural changes; time-dependent processes 


\section{INTRODUCTION}

Many techniques are at hand to investigate wood properties, ranging from very simple methods for point measurements down to in-depth three-dimensional characterization. Most of these are either limited to surface or sub-surface examination and/or destructive in nature. A very powerful addition to the existing modalities is X-ray computed tomography (X-ray CT). Tomography is an extension of radiography, i.e. the recording of a shadow image of an optically opaque object using penetrating radiation and a recording medium. For a detailed history of tomography one can read Webb (1990). The purpose of tomography is to obtain a three-dimensional representation of the composition and morphology of the object in a non-destructive way. Basically the 3D object under study is reconstructed based on a set of 2D projections (radiographies) taken from different angles by rotating the sample around a defined axis. In the case of $\mathrm{X}$-ray tomography, X-rays are used as a probe to study objects. X-rays typically have a wavelength below $10 \mathrm{~nm}$ and they are attenuated less easily than electrons and visible light. More importantly, their penetrating power is largely dependent on their energy, which is directly related to their wavelength, making it possible to adjust the energy of the source to the type of sample under investigation, depending on size, composition, etc. (Vlassenbroeck 2009). Furthermore, the ability to extract the chemical and densitometric properties of an object from X-ray projections is therefore related to the nature of the interactions between the radiation and the material. These interactions are heavily dependent on the density and composition, allowing to use the transmitted radiation to reveal these properties. Over the years the resolution of CT imaging systems has steadily improved, thanks to the significant progress both in hard- and software. Current state-of-the art lab-based systems are clearly coming of age. Depending on the resolutions required, different manufacturers deliver different systems for non-medical purposes. In addition to the commercial available systems, many groups build their own scanners for specific research purposes, differing in the type of material that has to be scanned, the required specimen size, energy level, etc. X-ray tomography has become a well-established technique and its multi-purpose use is widely recognized in wood science and technology. The number of papers with focus on lab-based X-ray tomography for fundamental research as well as its use as a tool for structural analysis is steadily increasing. A selection of different topics for which lab-based X-ray tomography can be used, shows the versatile employability in both static as dynamic experimental set-ups: wood anatomy (a.o. Van den Bulcke et al. 2008; 2009a), structural wood vessel analysis (a.o. Hass et al. 2010; Brodersen et al. 2011), moisture dynamics (a.o. Lazarescu et al. 2010; Derome et al. 2011), analysis on from wood derived materials (a.o. Faessel et al. 2005; Walther 2006; Walther and Thoemen 2009), etc. The non-destructive internal probing of a material at different scales, ranging from macroscopic down to microscopic level, is a significant advantage. Moreover, thanks to the non-destructive nature of the scanning process, one can monitor and quantify any time-dependent process such as structural changes owing to modification, fungal growth, water movement, weathering processes, etc. Such a technique can, therefore, play an important role in the characterisation of modified wood products. Wood modification has been a field of research for over a century (Rowell 2006; Esteves and Pereira 2009), covering a large range of methods that can be either chemical or thermal in nature, or a combination of both, aiming at an improvement of wood properties. The general awareness of limited natural wood resources as well as an incremental use of domestic, less durable wood species, has been a trigger for a recent increased interest in 
wood modification. Modifying wood mainly aims at reinforcing resistance against physical weathering and biological degradation by changing its chemistry and/or structure. By doing so there is a measurable change of the basic wood characteristics such as strength, colour, texture, structure, chemical composition, etc. It is essential to map these property changes before and after treatment to assess both the level of change and the effective resistance to come to a proper dose-response interpretation of the treatment, as well as a quality indicator for established treatments. X-ray tomography can be the pre-eminent technique to do so.

This paper elaborates on the wide range of possibilities of X-ray tomography as a tool for advanced static and dynamic analysis for wood research in general and more specifically on modified wood in its broadest sense. Examples on unmodified wood are presented too, yet all concepts and approaches discussed here are considered transferable to and most useful in the field of wood modification.

\section{EXPERIMENTAL METHODS}

The scanner used at Woodlab-UGent is developed at UGCT, the Ghent University Centre for X-ray Tomography (www.ugct.ugent.be). The scanner is similar to the one as described in Masschaele et al. (2007) and used in Van den Bulcke et al. (2009c; 2011a; b; 2012) and consists of two X-ray tubes and two X-ray detectors, specifically designed to obtain very high resolution scans as well as scans of larger objects. The system offers a large range of operational freedom, all combined in versatile acquisition routines (standard or fast scanning, tiling, helix, etc.). It has a generic in-house developed CT scanner control software platform (Dierick et al. 2010) that allows full control of the scanner hardware. Reconstruction of the scans is performed with Octopus, a tomography reconstruction package for parallel, cone-beam and helical geometry (Vlassenbroeck et al. 2007) and includes phase-retrieval and correction algorithms (Paganin et al. 2002; Grosso et al. 2006; De Witte et al. 2009). As the system can be used in many fields of wood research, several examples of scans performed with Nanowood are given on different types of materials, including different sizes of wood specimens, wood cores, plywood, etc.

\section{RESULTS AND DISCUSSION}

In general high resolution X-ray tomography can contribute considerably to research and development in wood science and technology in general and wood modification more specifically. Depending on the mode of action of the treatment, structural and/or chemical changes are under investigation on different levels. Treatability aspects are valid when comparing wood species (e.g. the role of refractory wood species and heartwood zones) and when discussing the modification processes for engineered wood products and wood based panels. Main interest is however in assessing both qualitatively and quantitatively the impact of different parameters on the modified product as well as characterisation in relation to performance. In this respect 4 focus areas can be identified: treatment level, dimensional stability, biological durability and wood anatomical changes. These are discussed and exemplified below in a framework of both static and dynamic tomography.

\section{Static tomography}


Straightforward analysis focuses on the visualization and qualitative investigation of modified wood at different spatial scales. Thanks to the flexible set-up of the scanner, various sample sizes and resolutions can be obtained, enabling broad distribution patterns of modification throughout blocks of treated wood as well as probing the modification down to the cell wall level. The system is capable of scanning samples of $37 \mathrm{~cm}$ in diameter and a maximal length of approximately $20 \mathrm{~cm}$ with a resolution of $0.2 \mathrm{~mm}$ down to approximately $400 \mathrm{~nm}$ for objects that have about the size of a splinter. Scan times range from several minutes up to several hours depending on the required quality and resolution. One is always confronted with a trade-off between the signal-tonoise ratio and necessity of stability during scanning, as such scan settings (sourcedetector distance, source-object distance, tube power, exposure time, \#projections, etc) are attuned to the research question at hand. A multi-resolution top-down approach for tomographic wood microscopy (Mannes et al. 2010) is exemplified for an untreated wood species, ipé (Tabebuia spp.), at different scales. This is illustrated in Figure 1 using a cross-section of the scanned volumes. These images were taken with standard cone-beam tomography. For very high resolution scans, such as the rightmost image of Figure 1, phase contrast must be taken into account. Although conventional tomography is based on the attenuation of X-rays, both the amplitude and phase change when passing through an object. At very high resolution this effect is visible and can, in some cases, be beneficial to visualise small details, yet often the mixture of phase and amplitude hampers proper processing. Therefore, to mitigate this effect, phase contrast filtering is often applied (Boone et al. 2009; De Witte et al. 2009; Wernersson et al. 2013).

Structural analysis allows for analysis of treatability as can be deduced from the work of Svedström et al. (2012) on aspen and a series of examples given by Van den Bulcke et al. (2009a). The image processing chain is illustrated in Figure 2 for labelling of the vessel lumina of oak (Quercus spp.). Although only a single cross-section is shown, all algorithms run in three dimensions as shown in the resulting 3D rendering in Figure 3a. Similar results could be obtained with images acquired with standard light microscopy, SEM or another technique, yet these are mostly limited to visualization of the (sub)surface while internal features can only be revealed through sectioning or any other process of material removal, possibly creating artefacts as well. X-ray tomography on the other hand enables a one-to-one analysis of a sample before and after treatment in three dimensions, as such not limited to the surface. All analyses are performed with the inhouse developed software package Morpho+, containing an extensive set of highperformance 3D operations to obtain object segmentation, separation, and parameterization or to extract a 3D geometrical representation for further modelling (Brabant et al. 2011). First the original volume is pre-processed, applying bilateral filtering to remove noise without extensive smoothing, i.e. in order to keep sharp transitions such as edges. In a second step the optimal threshold level is chosen to segment vessel lumina. The latter can be used to map different objects and label them separately. Subsequently, a distance transformation can be calculated to classify objects according to their size, shape, etc. and to separate them optimally when connected. The final result of such a process is given in Figure 3a, showing a 3D image of the labelled vessel lumina of the oak sample under investigation. Figure $3 \mathrm{~b}$ is an example of fibre labelling on aspen (Populus tremula). The same principle is of course feasible for treated wood. Treating chemicals or derived polymers can be present mainly in the cell lumen or cell wall penetration can be envisaged. 
Anatomical pathways can be primarily through axial tissues consisting of vessels in hardwoods or earlywood tracheids in softwoods, but some complementary involvement of ray pathways is required to obtain adequate distributions. Additionally it is relevant to check on envelope or matrix treatment by assessing treatment gradients linked to treatment level for products like resins, oils, coatings and even for hydrophobation agents like siloxanes.

Chemical distribution is elaborated on in the paper of De Vetter et al. (2006), describing the use of X-ray tomography for the distribution analysis of organosilicon compounds in wood. Scholz and co-workers (2010a) explore the impregnation of waxes related to the anatomy of Scots pine sapwood (Pinus sylvestris) and beech (Fagus sylvatica) complementary to SEM. This kind of top-down approach gives the opportunity to investigate the structure in depth in a fast and non-destructive way, offering the possibility to combine with other analysis if necessary. Especially the latter one-on-one relation is highly important to anticipate the inherent biological variability. Similarly, the follow up research of Scholz and co-workers (2010b) uses X-ray tomography for quantification of the pore size and wax distribution, with comparison of these results with other techniques, showing the complementary functioning of non-destructive tomography. Also, Kucerova (2012) illustrates the use of X-ray tomography to measure the penetration of consolidant solutions into wood and Ahmed and co-authors (2013; in press) show the potential of CT scanning for studying preservative distribution in thermally modified wood.

An example of resin deposits on the walls of Scots pine sapwood tracheids is given in Figure 4a. The wood was treated with an aqueous solution of a methylolated melamine formaldehyde (MMF) resin, cured in a laboratory oven. The aim of this investigation was to localize the cured resin droplets and assess how the specific anatomy of a wood species influences the impregnation behaviour. Visualization and analysis of coatings can also be considered as a form of surface modification, resulting in full structural characterization (Van den Bulcke et al. 2010). Figure 4b illustrates the visualization of an opaque coating on Scots pine.

Assessment of dimensional stability is mainly linked to a dynamic analysis however differential scanning can allow verification of bulking effects of e.g. acetylation on specific parts of wood and the refractory nature preventing chemical penetration, e.g. poor treatment of Scots pine heartwood. As Boonstra and co-authors (2006) illustrated it can be useful to check the wood anatomical alterations of modified wood. Treating processes to obtain TMT products can initiate collapse or related features that can be quantified on anatomical structure level.

More advanced analysis includes connectivity before and after treatment, e.g. for fungal pathway analysis as illustrated in Van den Bulcke et al. (2008). High-resolution imaging of penetration routes in oak, beech, bamboo etc. are under investigation as well as glue barrier analysis. This enables verification of non-toxic treatments allowing fungi to grow into the wood matrix however without inducing rot. Pathway analysis was also developed by Hass and co-authors (2012) to study adhesive penetration in wood using synchrotron-based tomography.

The above-mentioned analyses derive quantitative structural information from the volumes but without the use of the data resulting from the underlying principle of a 
direct relation between greyscale and density. Although this relation is not straightforward and depending on the chemical composition as well, there is an opportunity of extracting densitometrical data from these volumes for wood as composition in most cases can be considered more or less constant. Briefly, the basic principle relies on the use of a reference material with a density approximating cell wall density and recalculating all 16 bit greyscale values accordingly. As such the scanned $3 \mathrm{D}$ volume is converted to actual densities. More information on the methodology and validation of the technique can be found in the paper by De Ridder and co-workers (2011), using helical X-ray tomography on limba (Terminalia superba) wood cores. Helical tomography is similar to standard cone-beam tomography, but instead of a circular movement, the sample describes a helical trajectory. Helical tomography has several advantages, especially when scanning elongated objects such as wood cores, but comes with a higher mechanical and mathematical complexity; reconstruction is based on the Katsevich algorithm (De Witte 2010). Helix scanning is used complementary to cone beam scanning enabling gradient analysis over cross-sections of trees (Van den Bulcke et al. 2012) and this can be used for verification of microdensitometric differences as a result of modification processes. An example to illustrate this potential is given in Figure 5 for non modified limba and Scots pine. It should be noted that the 1D profile given is an average of each cross-sectional slice taken in radial direction, i.e. the density is derived from actual 3D density data.

A similar principle can be used in the field of wood modification, when evaluating density changes of treatment, visualization and assessment of moisture, etc. by either sub-sampling of core-like samples of larger material, region of interest scanning or by tomography of the entire specimen if small enough.

\section{Time lapse and dynamic tomography}

Time lapse tomography is the analysis of the same sample at different times, such as the analysis of density changes during fungal attack (Van den Bulcke et al. 2011a), highresolution fungal growth monitoring (Van den Bulcke et al. 2009b), etc. In fact, the analysis of the effect of thermal treatment can be considered an example of time lapse tomography, when the same sample is scanned before and after treatment. An example of such possible changes is given in Figure 6 illustrating the shrinkage of thermally treated aspen. The treatment was carried out in a device made by wood thermal technology (WTT). Samples were placed in an autoclave and subjected to a specific thermal treatment consisting of three main stages: (1) temperature increase up to the modification temperature $\left(160{ }^{\circ} \mathrm{C}\right)$; $(2)$ holding at the modification temperature $(1 \mathrm{~h})$; (3) cooling. In the course of the process, as the water evaporated at a rate dependent on the treatment temperature in the chamber, the pressure increased, reaching 5-9 bars. For more information on the treatment process and microstructural, the reader is referred to Biziks et al. (in press).

Quantification of change in porosity, even on a tissue level, can help interpreting the treatment process. 3D image registration can also map the actual shrinkage of the sample on a voxel-by-voxel basis, as such also inferring on the stress-strain fields. The work of Forsberg and co-authors $(2008 ; 2010)$ is pioneering in that respect.

Furthermore time lapse tomography is key when analysing the impact of water and moisture content both related to dimensional changes and time of wetness (ToW) analysis. An example of combining moisture monitoring using a CMM (Continuous Moisture Monitoring) approach (Van den Bulcke et al. 2009c) and the effect of 
weathering thereon is given in the paper by Van den Bulcke and co-workers (2011b). Analysis revealed glue cracking and as such some plywood samples reached high moisture contents.

Dynamic tomography on the other hand refers to the actual monitoring of a dynamic process during scanning. For very fast processes ( $<1 \mathrm{~min})$, full tomographical scanning is currently difficult if not performed at synchrotron facilities. Synchrotron radiation has some unique properties, making it highly suitable for X-ray imaging. Since its high flux is concentrated into a cone beam with an extremely narrow opening angle, originating from a very small source area, imaging can be performed far away from the source and at very high speed, therefore ideal for dynamic tomography, such as is elaborated on in the papers by Derome et al. (2011) for the hysteretic behaviour of wood and Zauner et al. (2012) for the observation of plastic deformation of uniaxially compressed Norway spruce samples. Radiographies, however, can also be useful. Figure 7 a shows an example of a set-up for contact angle measurement and water penetration in a sample of MDF (Medium Density Fibreboard). Through image processing, only the water is made visible and penetration can be followed in time. For processes that are slower than 1 minute or for which a high image quality is not required, full 3D analysis of a timedependent phenomenon is feasible. Figure $7 \mathrm{~b}$ illustrates the penetration of water in plywood veneers. Water penetration was monitored for several hours and separated from the plywood by image processing.

Currently, faster scanning protocols are developed that will enable full tomographical scans at high-resolution in less than a minute to follow dynamic processes in 3D. Such fast scanning is also beneficial when working with living biological tissue in which stress and possible to damage due to radiation has to be reduced to the minimum (Van den Bulcke et al. 2009b). Clearly, implementation at lab-based systems is a continuing task.

\section{CONCLUSIONS}

The use of high-resolution X-ray computed tomography in wood science is increasing considerably. Early research with this technique was mainly focusing on its applicability as an advanced imaging tool to reveal the internal structure non-destructively, but the last decade the wood science community clearly has discovered it as a modality for quantitative research, not the least owing to the significant progress in hardware, the massive computational resources available and the commercial availability of userfriendly table-top systems. Wood is especially challenging because of its hierarchical nature, demanding a multi-scale approach with regard to three-dimensional imaging. The enormous potential of flexible X-ray tomography scanners such as Nanowood can result in fast 3D characterization of the same material before and after treatment for modified wood, following dynamic processes with time-lapse scanning, etc. leading to new insights and improved treatment procedures. The abovementioned examples are only a small part from a long list of possible experimental set-ups and scanning techniques and this is expected to increase substantially in the near future. Together with other equipment for semi- to non-destructive testing, it offers wood research with the possibility to go beyond current state-of-the-art. New scanning set-ups such as dualenergy and phase-contrast, as well as reconstruction algorithms such as the family of iterative techniques, will lead to faster scanning and faster and improved reconstruction 
and visualization of different, difficult to follow and discern phenomena and phases. Furthermore, the hierarchical nature of wood necessitates its study on different spatial scales. As phenomena emerging on a high resolution have an impact on all other resolutions, multi-resolution imaging of a complex material such as wood in general, and modified wood more specifically, is one of the major challenges.

\section{ACKNOWLEDGEMENTS}

The authors greatly acknowledge all colleagues at Woodlab-UGent and UGCT for their continuing effort in testing and improving the wide variety of experiments and scanners, as well as all international colleagues for fruitful discussion and collaboration to challenge boundaries within X-ray CT wood based research. The Special Research Fund of the Ghent University (BOF) is acknowledged for the doctoral grant to Loes Brabant. This equipment was obtained through the project SimForTree of IWT Flanders (Strategic Basic Research - SBO 060032) and is available for research under the conditions established in general by UGCT and also accessible under the EU Infrastructure project Trees4Future as Transnational Access equipment (Project no. 284181).

(C) All pictures are property of UGCT and/or WOODLAB (or mentioned otherwise). It is not allowed to use them without permission. 


\section{REFERENCES}

Ahmed, S. A., Sehlstedt-Persson, M., Hansson, L. and Morén, T. 2013. Evaluation of preservative distribution in thermally modified European aspen and birch boards using computed tomography and scanning electron microscopy. J. Wood Sci., 59, 57-66.

Ahmed, S.A., Hansson, L. and Morén, T. 2013. Distribution of preservatives in thermally modified Scots pine and Norway spruce sapwood. Wood Science and Technology, 47, 499-513.

Biziks, V., Andersons, B., Beḷkova, L., Kapača, E. and Militz, H. in press. Changes in the microstructure of birch wood after hydrothermal treatment. Wood Sci. Technol.

Boone, M., De Witte, Y., Dierick, M., Van den Bulcke, J., Vlassenbroeck, J. and Van Hoorebeke, L. 2009. Practical use of the modified Bronnikov algorithm in micro-CT, Nucl. Instrum. Meth. A, 267, 1182-1186.

Boonstra, M. J., Rijsdijk, J. F., Sander, C., Kegel, E., Tjeerdsma, B. F., Militz, H., Van Acker, J. and Stevens, M. 2006. Physical aspects of heat-treated wood. Part 1. Softwoods. Maderas. Ciencia y tecnología, 8, 193-208 \& Part 2. Hardwoods. Maderas. Ciencia y tecnología, 8, 209-217.

Brabant, L., J. Vlassenbroeck, Y. De Witte, V. Cnudde, M. Boone, J. Dewanckele and Van Hoorebeke, L. 2011. Three-dimensional analysis of high-resolution X-ray computed tomography data with Morpho+. Microsc. Microanal., 17, 252-263.

Brodersen, C. R., Lee E. F., Choat, B., Jansen, S., Phillips, R. J., Shackel K. A., McElrone, A. J. and Matthews, M. A. 2011. Automated analysis of three-dimensional xylem networks using high-resolution computed tomography. New Phytol., 191, 1168 1179.

De Ridder, M., Van den Bulcke, J., Vansteenkiste, D., Van Loo, D., Dierick, M., Masschaele, B., De Witte, Y., Mannes, D., Lehmann, E., Beeckman, H., Van Hoorebeke, L. and Van Acker, J. 2011. High-resolution proxies for wood density variations in Terminalia superba. Ann. Bot-London, 107, 293-302.

Derome, D., Griffa, M., Koebel, M. and Carmeliet, J. 2011. Hysteretic swelling of wood at cellular scale probed by phase-contrast X-ray tomography. J. Struct. Biol., 173, 180190.

De Vetter, L., Cnudde, V., Masschaele, B., Jacobs, P. and Van Acker, J. 2006. Detection and distribution analysis of organosilicon compounds in wood by means of SEM-EDX and micro-CT. Mater. Charact., 56, 39-48.

De Witte, Y., Boone, M., Vlassenbroeck, J., Dierick, M. and Van Hoorebeke, L. 2009. Bronnikov-aided correction for X-ray computed tomography. J. Opt. Soc. Am. A, 26, 890-4. 
De Witte, Y. 2010. Improved and practically feasible reconstruction methods for high resolution $X$-ray tomography. $\mathrm{PhD}$ thesis, Ghent University, Belgium.

Dierick, M., Van Loo, D., Masschaele, B., Boone, M. and Van Hoorebeke, L. 2010. A LabVIEW® based generic CT scanner control software platform. J. X ray Sci. Technol., $18,451-461$.

Esteves, B. M., Pereira, H. M. 2009. Wood modification by heat treatment: a review. Bioresour., 4, 370-404.

Faessel, M., Delisée, C., Bos, F. and Castéra, P. 2005. 3D Modelling of random cellulosic fibrous networks based on X-ray tomography and image analysis. Comp. Sci. Technol., 65, 1931-1940.

Forsberg, F., Mooser, R., Arnold, M., Hack, E. and Wyss, P. 2008. 3D micro-scale deformations of wood in bending: Synchrotron radiation $\mu \mathrm{CT}$ data analyzed with digital volume correlation. J. Struct. Biol., 164, 255-262.

Forsberg, F. , Sjödahl, M. , Mooser, R. , Hack, E. and Wyss, P. 2010. Full threedimensional strain measurements on wood exposed to three-point-bending: analysis by use of digital volume correlation applied to synchrotron radiation micro-computed tomography image data. Strain, 46, 47-60.

Groso, A., Abela, R. and Stampanoni, M. 2006. Implementation of a fast method for high resolution phase contrast tomography. Opt. Express, 14, 8103-8110.

Hass, P., Wittel, F. K., McDonald, S. A., Marone, F., Stampanoni, M., Herrmann, H. J. and Niemz, P. (2010). Pore space analysis of beech wood: The vessel network. Holzforschung, 64, 639-644.

Hass, P., Wittel, F. K., Mendoza, M., Herrmann, H. J. and Niemz, P. 2012. Adhesive penetration in beech wood: experiments. Wood Sci. Technol., 46, 243-256.

Kucerova, I. 2012. Methods to measure the penetration of consolidant solutions into 'dry' wood. J. Cult. Herit., 13(3). 191-195.

Lazarescu, C., Watanabe, K. and Avramidis, S. 2010. Density and moisture profile evolution during timber drying by CT scanning measurements. Dry. Technol., 28, 460467.

Mannes, D., Marone, F., Lehmann, E., Stampanoni, M. and Niemz, P. 2010. Application areas of synchrotron radiation tomographic microscopy for wood research. Wood Sci. Technol., 44, 67-84.

Masschaele, B. C., Cnudde, V., Dierick, M., Jacobs, P., Van Hoorebeke, L. and Vlassenbroeck, J. 2007. UGCT: New X-ray radiography and tomography facility. Nucl. Instrum. Meth. A, 580, 266-269. 
Paganin, D. M., Mayo, S. C., Gureyev, T. E., Miller, P. R. and Wilkins S. W. 2002. Simultaneous phase and amplitude extraction from a single defocused image of a homogeneous object. J. Microsc., 206, 33-40.

Rowell, R. M. 2006. Chemical modification of wood : a short review. Wood Mater. Sci. Eng., 1, 29-33.

Scholz, G., Van den Bulcke, J., Boone, M., Zauer, M., Baucker, E., Van Acker, J. and Militz, H. 2010a. Investigation on wax-impregnated wood. Part 1: Microscopic observations and 2D X-ray imaging of distinct wax types. Holzforschung, 64, 581-585.

Scholz, G., Zauer, M., Van den Bulcke, J., Van Loo, D., Pfriem, A., Van Acker, J. and Militz, H. 2010b. Investigation on wax-impregnated wood. Part 2: Study of void spaces filled with air by $\mathrm{He}$ pycnometry, $\mathrm{Hg}$ intrusion porosimetry, and 3D X-ray imaging. Holzforschung, 64, 587-593.

Svedström, K., Lucenius, J., Van den Bulcke, J., Van Loo, D., Immerzeel, P., Suuronen, J.-P., Brabant, L., Van Acker, J., Saranpää, P. and Fagerstedt, K. 2012. Hierarchical structure of juvenile hybrid aspen xylem revealed using X-ray scattering and microtomography. Trees - Struct. Func., 26, 1793-1804.

Van den Bulcke, J., Masschaele, B., Dierick, M., Van Acker, J., Stevens, M. and Van Hoorebeke, L. 2008. Three-dimensional imaging and analysis of infested coated wood with X-ray submicron CT. Int. Biodeterior. Biodegrad., 61, 278-286.

Van den Bulcke, J., Boone, M., Van Acker, J., Stevens, M. and Van Hoorebeke, L. 2009a. X-ray tomography as a tool for detailed anatomical analysis. Ann. For. Sci., 66, 508.

Van den Bulcke, J., Boone, M., Van Acker, J. and Van Hoorebeke, L. 2009b. ThreeDimensional X-Ray Imaging and Analysis of Fungi on and in Wood. Microsc. Microanal., 15, 395-402.

Van den Bulcke, J., Van Acker, J. and De Smet, J. 2009c. An experimental set-up for real-time continuous moisture measurements of plywood exposed to outdoor climate. Build Environ, 44, 2368-2377.

Van den Bulcke, J., Boone, M., Van Acker, J. and Van Hoorebeke, L. 2010. Highresolution X-ray imaging and analysis of coatings on and in wood. J. Coat. Technol. Res., 7, 271-277.

Van den Bulcke, J., De Windt, I., Defoirdt, N. and Van Acker, J. 2011a. Nondestructive evaluation of wood decay. The International Research Group on Wood Protection. Document No. IRG/WP/11-20479.

Van den Bulcke, J., De Windt, I., Defoirdt, N., De Smet, J. and Van Acker, J. 2011b. Moisture dynamics and fungal susceptibility of plywood. Int. Biodeterior. Biodegrad., $65,708-716$. 
Van den Bulcke, J., De Ridder, M., Dié, A., Toirambé, B., Vansteenkiste, D., Hubau, W., Van Loo, D., Dierick, M., Masschaele, B., De Witte, Y., Beeckman, H., Van Hoorebeke, L. and Van Acker, J. 2012. Microdensitometry of tropical wood using helical X-ray tomotgrpahy: a proxy for dendroclimatology and forest management. In: Proceedings of 2012 IUFRO Conference on Division 5 Forest Products, p. 160.

Vlassenbroeck, J. 2009. Advances in laboratory-based X-ray microtomography. $\mathrm{PhD}$ thesis, Ghent University, Belgium.

Vlassenbroeck, J., Dierick, M., Masschaele, B., Cnudde, V., Van Hoorebeke L. and Jacobs, P. 2007. Software tools for quantification of X-ray microtomography at the UGCT. Nucl. Instrum. Meth. A, 580, 442-445.

Walther, T. (2006). Methoden zur qualitativen und quantitativen Analyse der Mikrostruktur von Naturfaserwerkstoffen. PhD thesis, University Hamburg, Germany.

Walther, T. and Thoemen, H. (2009). Synchrotron X-ray microtomography and 3D image analysis of medium density fiberboard (MDF). Holzforschung, 63, 581-587.

Webb, S. 1990. From the watching of the shadows, the origins of radiological tomography, Bristol/New York: Adam Hilger.

Wernersson, E. L. G., Boone, M. N., Van den Bulcke, J., Van Hoorebeke, L. and Luengo Hendriks, C. L. (2013). Postprocessing method for reducing phase effects in reconstructed microcomputed-tomography data. J. Opt. Soc. Am. A, 30, 455-461.

Zauner, M., Keunecke, D., Mokso, R., Stampanoni, M., and Niemz, P. 2012. Synchrotron-based tomographic microscopy (SbTM) of wood: development of a testing device and observation of plastic deformation of uniaxially compressed Norway spruce samples. Holzforschung, 66, 973-979. 


\section{FIGURE CAPTIONS}

Figure 1: Cross-sections of Tabebuia spp. at different scales (length of image given below each image)

Figure 2: Vessel segmentation and labelling in oak, a: original, b: bilateral filtered, c: thresholded vessel lumina, d: labelled vessel lumina, e: distance transform, f: overlay of size-labelled vessel lumina on the original cross-section (diameter of sample approximately $12 \mathrm{~mm}$ ).

Figure 3: Vessel lumina segmentation in oak (a; diameter approximately $12 \mathrm{~mm}$ ) and fibrefoc lumina segmentation in aspen (b; cross-sectional dimensions approximately 0.4 $\mathrm{mm} \times 0.5 \mathrm{~mm})$.

Figure 4: Resin deposits on Scots pine tracheid walls (a; longest edge of volume approximately $0.25 \mathrm{~mm}$ ) and an opaque coating (red) on Scots pine (b; ). For the latter the wood is virtually removed to illustrate the rough penetration profile of the coating in the tracheids.

Figure 5: 3D volume of a core of limba (a; diameter of core approximately $5 \mathrm{~mm}$ ) and of Scots pine (b; cross-section approximately $3 \times 3 \mathrm{~mm}$ ) and corresponding microdensitometrical profile with ring width and age (c).

Figure 6: Aspen before (greyish) and after (brownish) thermal treatment (cross-section approximately 0.4 x $0.5 \mathrm{~mm}$ ).

Figure 7: Water droplet penetration in an MDF (Medium Density Fibreboard) panel (a1 to a3); penetration of water in plywood in 2D: b1 illustrates the cylinder containing the water on top of the plywood panel (darker lines $=$ glue) and b2 illustrates the visualization of the water in the first veneer; a 3D version of water penetration (blue) in the first veneer of plywood is shown in (c). 
Figure 1
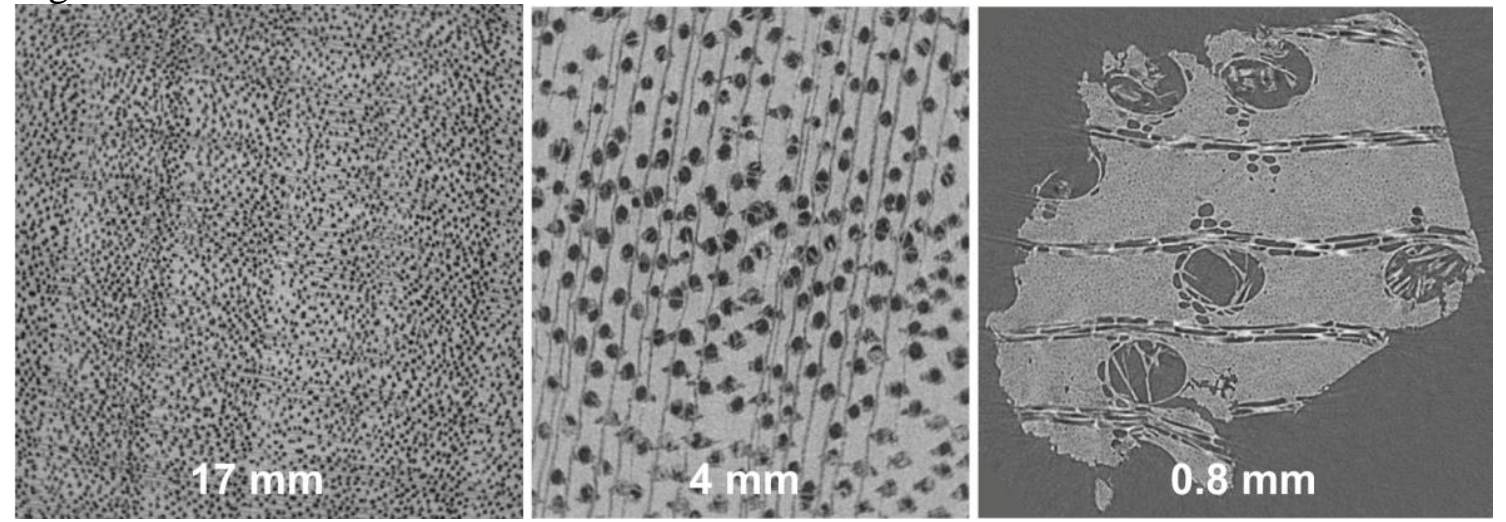
Figure2
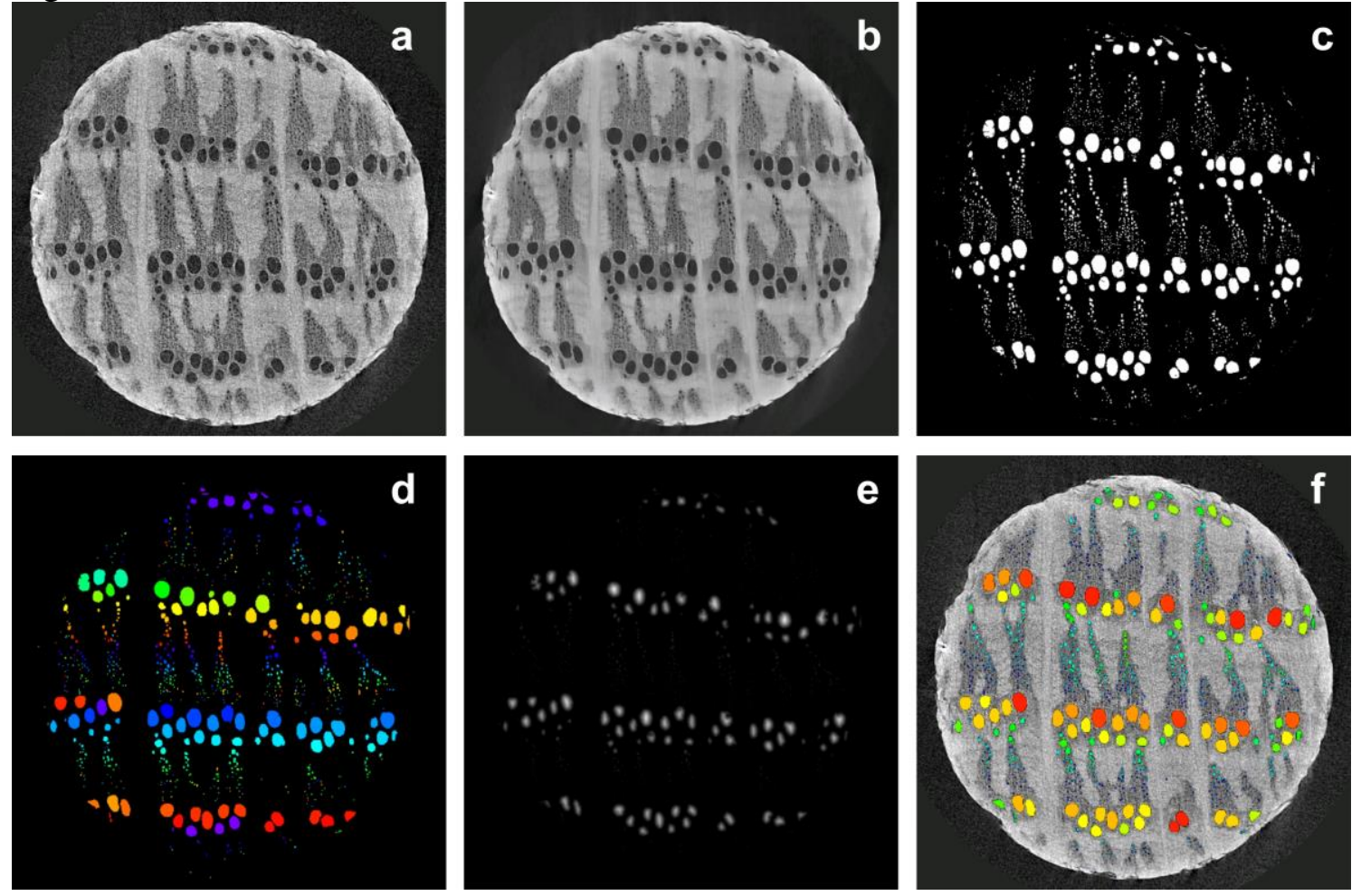
Figure3
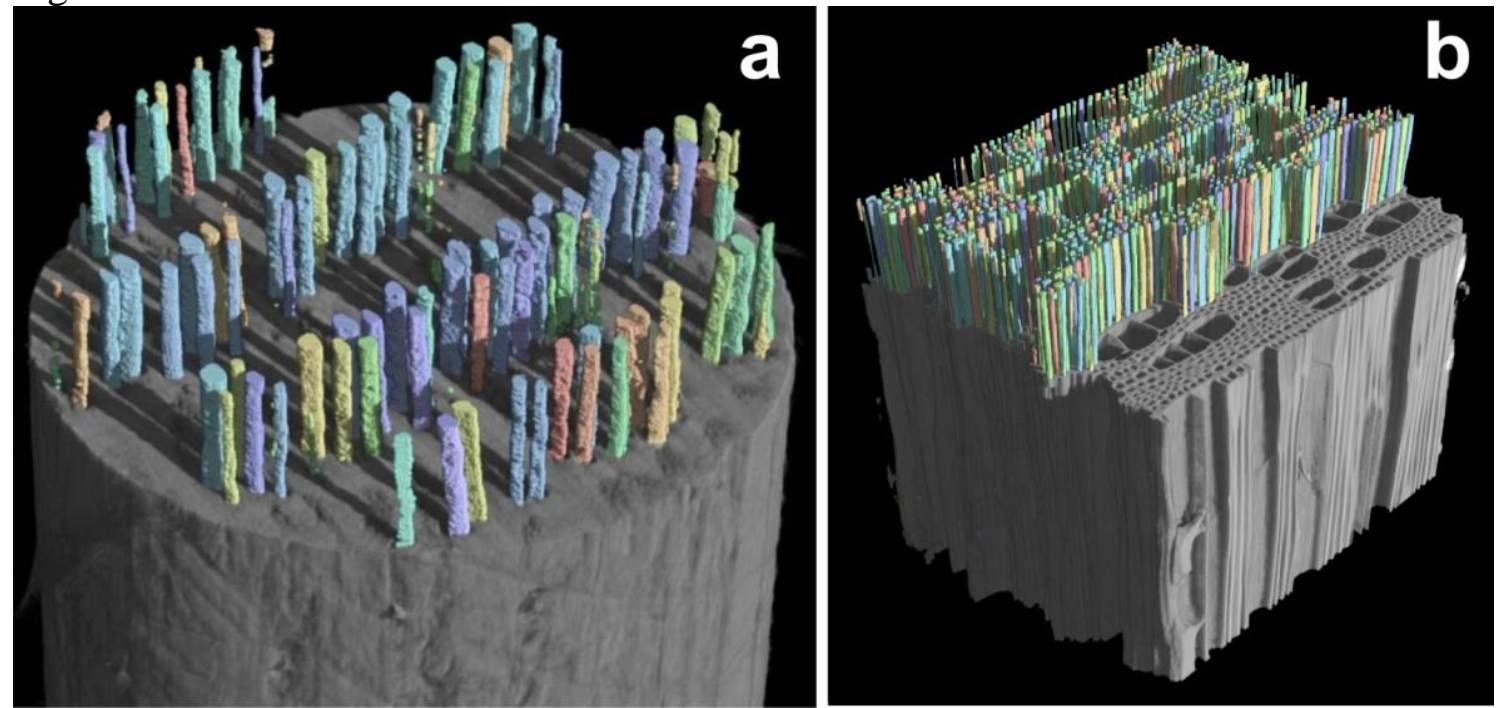
Figure4
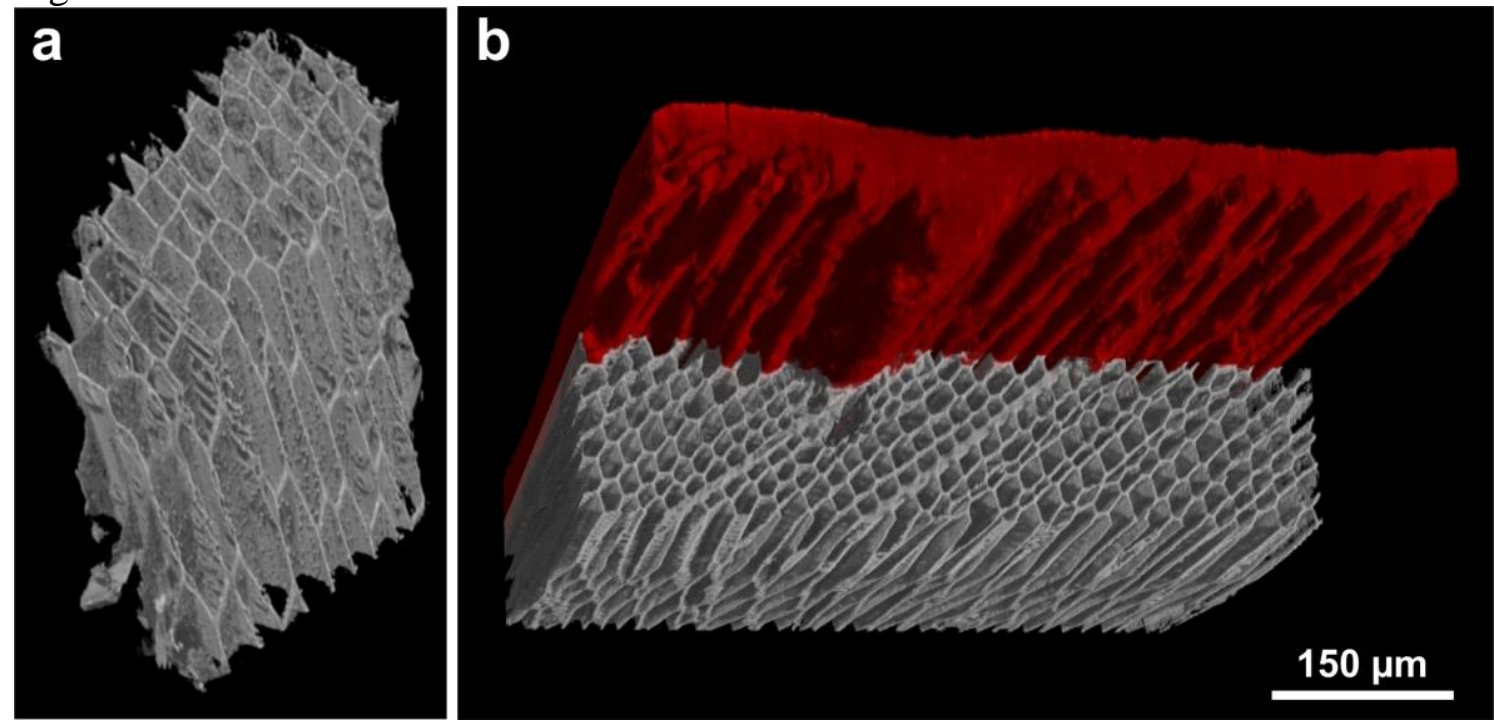
Figure5
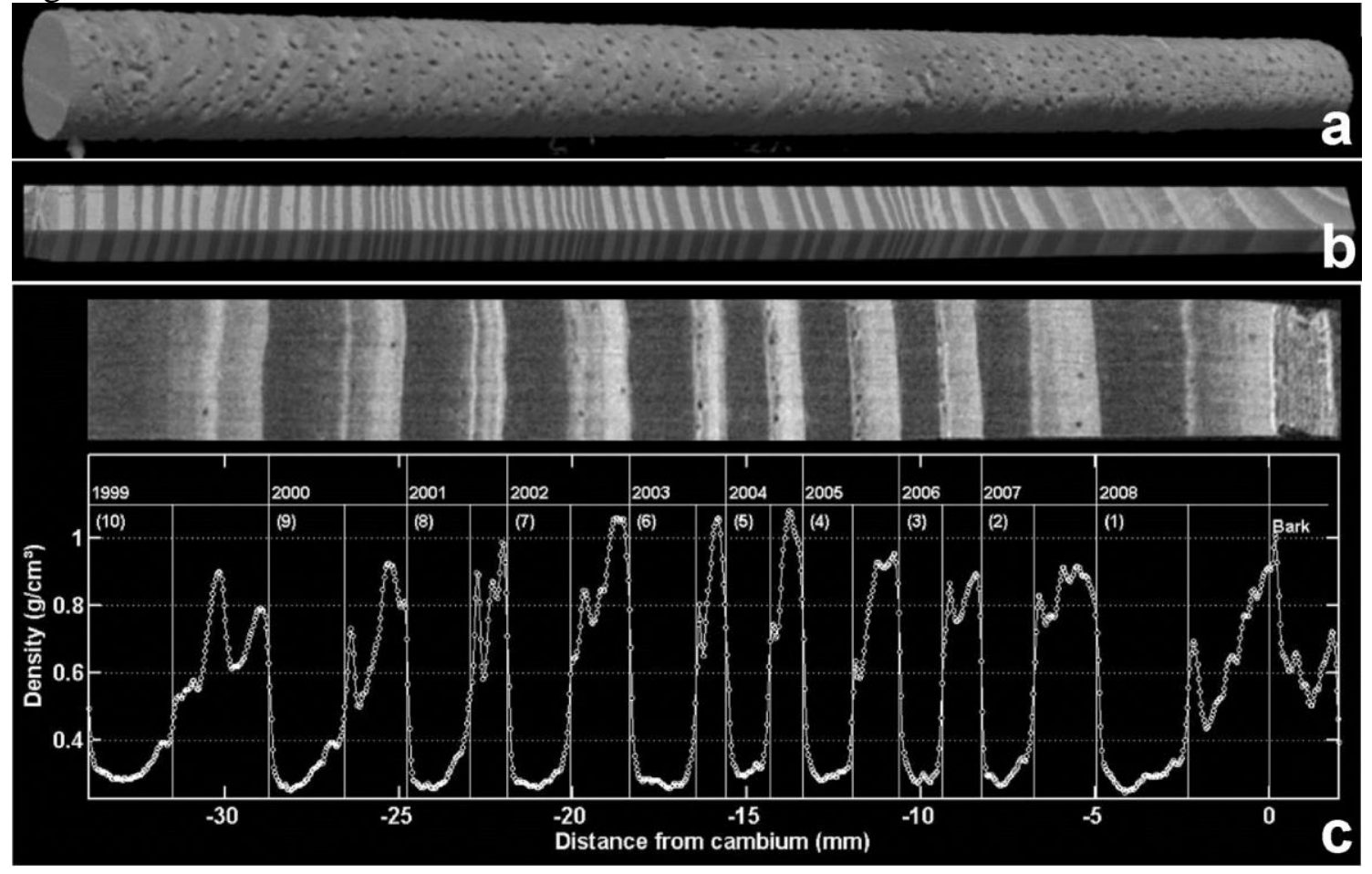
Figure6
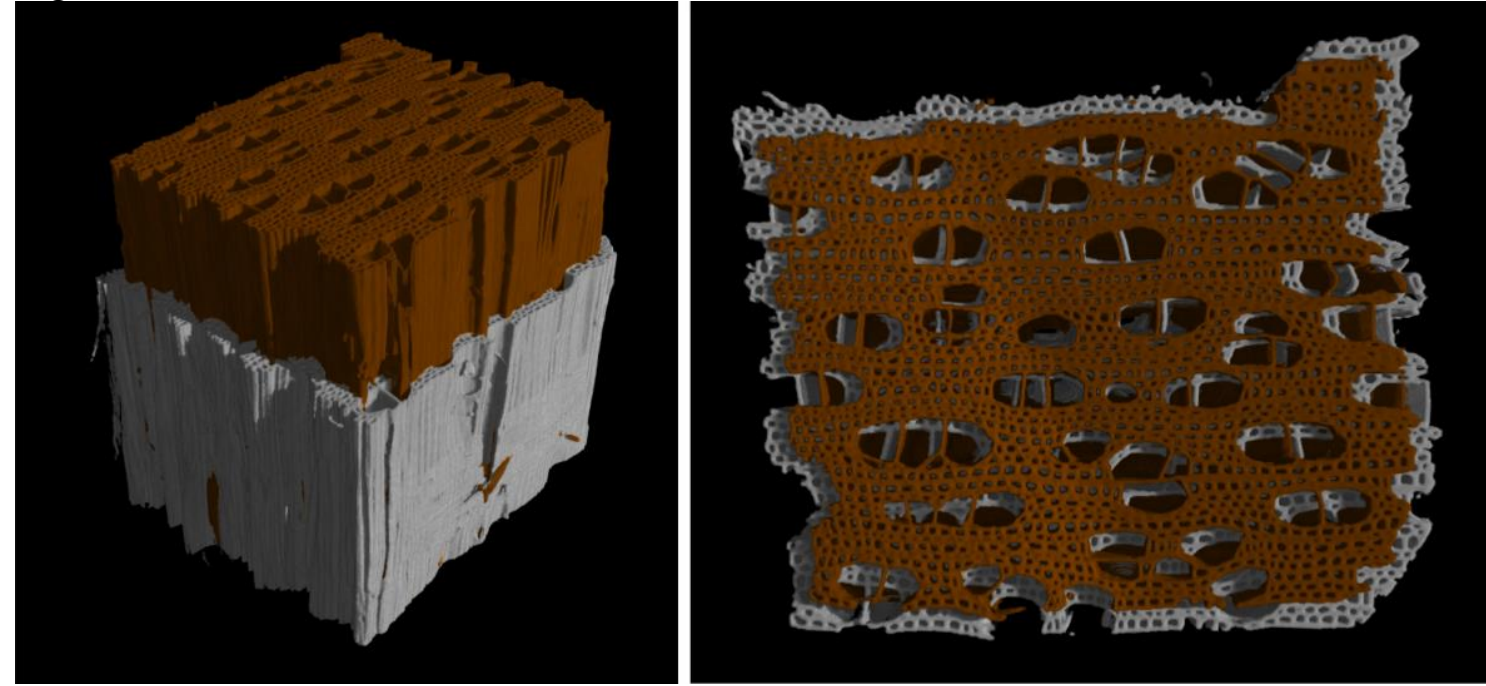
Figure7

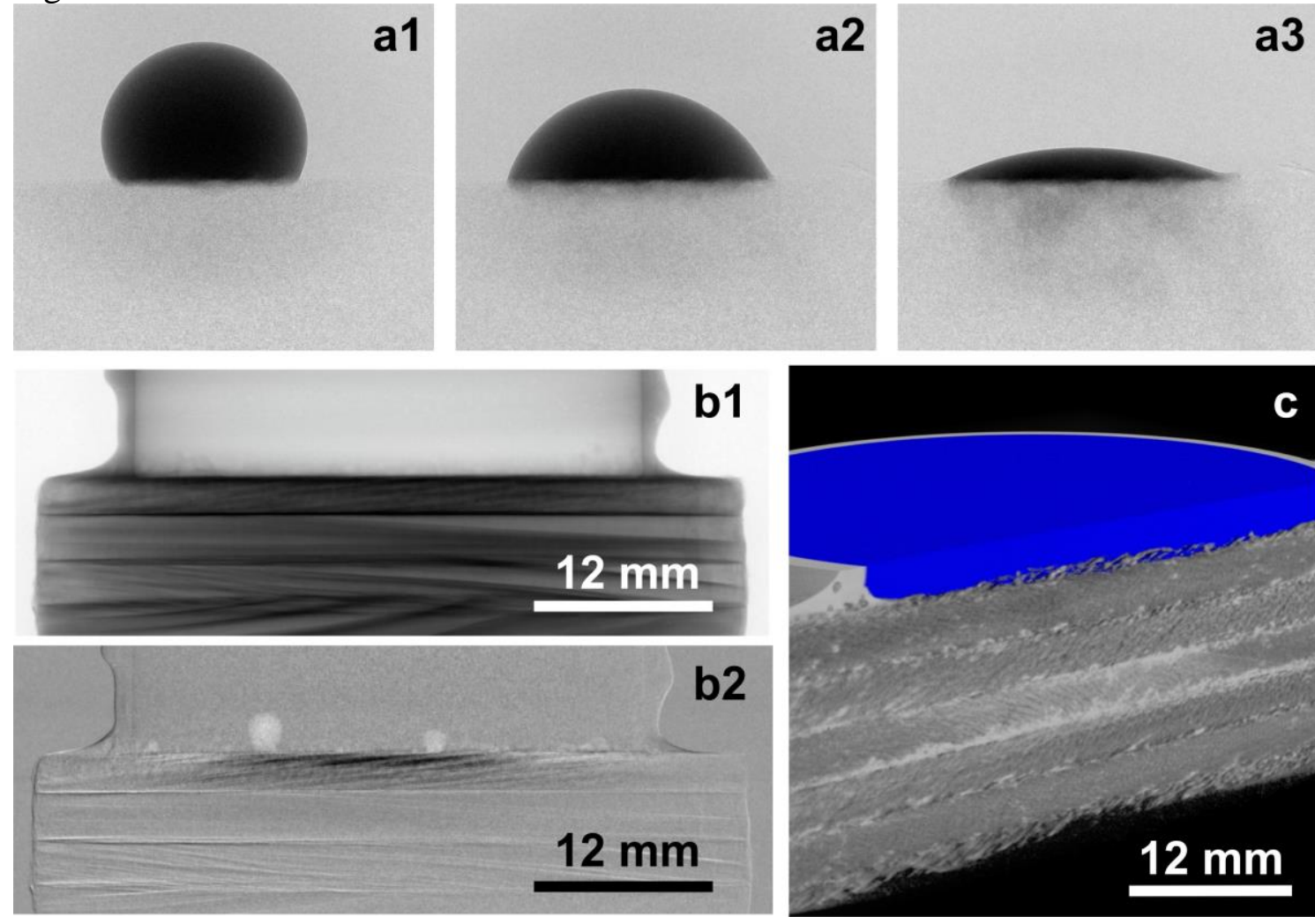

